\title{
DEVELOPMENT OF SOFTWARE FOR THE CREATION OF NEW MATERIALS WITH HYBRID PROPERTIES
}

\author{
IKUO TANABE \\ Dept. of Mechanical Engineering, Nagaoka University of Technology, Japan
}

\begin{abstract}
Since the beginning of the $21^{\text {st }}$ century, the importance to manufacture products that involve highquality, hybrid properties, multi-functionality, low-cost, and environmentally-friendly characteristics has been highlighted in the development of new ideas and technologies. Therefore, given that the development of new materials has been following the same trend, a software for the creation of new materials with hybrid properties was developed and evaluated. The developed software involved and calculated several properties, such as density, Young's modulus, coefficient of linear expansion, specific heat and thermal conductivity. This software was composed of the following two functions: (1) the calculation of the combination and ratio of constituent materials to create a composite material that achieves certain desired properties, and (2) the calculation of the properties shown by the generated composite material based on the combination and ratio of its constituent materials. Subsequently, a three-dimensional functional gradient material (FGM) was manufactured and evaluated based on the developed software. It was concluded from the evaluation that; (1) the proposed software was able to calculate properties such as density, Young's modulus, coefficient of linear expansion, specific heat and thermal conductivity; (2) the software was useful for the development of a three-dimensional functional gradient material.

Keywords: software, new material, hybrid property, three-dimensional functional gradient material, functionally graded material.
\end{abstract}

\section{INTRODUCTION}

Since the beginning of the $21^{\text {st }}$ century, the importance to manufacture products that involve high-quality [1], hybrid properties [2], multi-functionality [3], low-cost and environmentally-friendly characteristics [4] has been highlighted in the development of new ideas and technologies. Therefore, given that the development of new materials has been following the same trend, a software for the creation of new materials with hybrid properties was developed and evaluated. The developed software involved and calculated several properties such as density, Young's modulus, coefficient of linear expansion, specific heat and thermal conductivity. This software was composed of the following two functions (1) the calculation of the combination and ratio of constituent materials to create a composite material that achieves certain desired properties and (2) the calculation of the properties shown by the generated composite material based on the combination and ratio of its constituents. Particularly, the calculation involved to achieve the desired properties was meant to support up to 5 property constraints simultaneously (i.e. Young's modulus, density, coefficient of linear expansion, specific heat and thermal conductivity). Concurrently, the order of priority and the permissible range for each property was defined as part of the software input. Thus, it was considered that this software could be effectively used for the design and manufacture of new composite materials with multiple hybrid properties.

\section{PHYSICAL PROPERTIES CALCULATION MODELS FOR A NEW COMPOSITE}

The proposed models shown below were developed for this research [5] and were used for the calculation of properties such as the Young's modulus, density, coefficient of linear 
expansion and specific heat. On the other hand, the Russel model [6] was used for the calculation of the thermal conductivity. The used suffixes were the following: -s was fine aggregate, -g was rough aggregate, -e was bonding aggregate (e.g. epoxy resin), -a was air and -c was concrete or mortar. All composite combinations in the software used concrete, a porous material or a sintered compact. Here, volume percentage was calculated by eqn (1).

$$
\begin{gathered}
V \mathrm{~s}=W \mathrm{~s} \cdot \rho_{\mathrm{c}} / \rho_{\mathrm{s}} \\
V \mathrm{~g}=W \mathrm{~g} \cdot \rho_{\mathrm{c}} / \rho_{\mathrm{g}} \\
V \mathrm{e}=W \mathrm{e} \cdot \rho_{\mathrm{c}} / \rho_{\mathrm{e}} \\
V \mathrm{a}=100-(V \mathrm{~s}+V \mathrm{~g}+V \mathrm{e}),
\end{gathered}
$$

where $V$ was volume percentages [\%], $W$ was weight percentage [\%], $\rho$ was density $\left[\mathrm{kg} / \mathrm{m}^{3}\right]$. Here, in the case of the porous material or the sintered compact $(W e=0)$ values of $V \mathrm{e}=W \mathrm{e}=10^{-6}$ were employed.

The thermal conductivity was calculated by eqn (2) [6]. Here, t was continuous layer and $\mathrm{d}$ was non-continuous layer.

$$
\lambda \mathrm{c}=\lambda \mathrm{t} \frac{K \cdot V_{\mathrm{d}}^{2 / 3}+\left(1-V_{\mathrm{d}}^{2 / 3}\right)}{K \cdot\left(V_{\mathrm{d}}^{2 / 3}-V_{\mathrm{d}}\right)+\left(1-V_{\mathrm{d}}^{2 / 3}+V_{\mathrm{d}}\right)},
$$

where $\lambda$ was the thermal conductivity $[\mathrm{W} /(\mathrm{m} / \mathrm{K})]$ and $K$ was $\lambda \mathrm{d} / \lambda \mathrm{c}$. In the case of concrete, as shown in Fig.1, the thermal conductivity of the mortal 1, where the continuous layer was the bonding aggregate and the non-continuous layer was the fine aggregate, was calculated in first instance. Then, the thermal conductivity of the mortal 2, where the continuous layer was the mortal 1 and the non-continuous layer was a middle aggregate, was calculated. Moreover, the thermal conductivity of the concrete when the continuous layer was the mortal 2 and the non-continuous layer was a coarse aggregate was calculated. Here, in the case of the porous material or the sintered compact $(W e=0)$ values of $V \mathrm{e}=W \mathrm{e}=10^{-6}$ were used.

The specific heat was calculated by eqn (3) [5], [7].

$$
\begin{gathered}
C_{\mathrm{c}}=[W \mathrm{~s} \cdot C \mathrm{~s}+W \mathrm{~g} \cdot C \mathrm{~g}+W \mathrm{e} \cdot C \mathrm{e}+\{(100- \\
(W \mathrm{~s}+W \mathrm{~g}+W \mathrm{e})\} C \mathrm{a}] / 100,
\end{gathered}
$$

where $C$ was specific heat $[\mathrm{kJ} /(\mathrm{kgK})]$ and $W$ was weight percentage [\%]. Here, in the case of the porous material or the sintered compact $(W \mathrm{e}=0)$ values of $V \mathrm{e}=W \mathrm{e}=10^{-6}$ were utilized.

The coefficient of linear expansion was calculated by the equation (4).

$$
\alpha_{\mathrm{c}}=\frac{\alpha_{\mathrm{d}} \cdot V_{\mathrm{d}}+\alpha_{\mathrm{t}}\left\{1+(Y-1)+V_{\mathrm{d}}^{1 / 3}-Y \cdot V_{\mathrm{d}}\right\}}{1+(Y-1)\left(V_{\mathrm{d}}^{1 / 3}-V_{\mathrm{d}}\right)}
$$

where $\alpha$ was the coefficient of linear expansion [1/K], $Y$ was $E_{\mathrm{t}} / E_{\mathrm{d}}$ and $E$ was the Young's modulus [GPa]. Here, in the case of concrete, the coefficient of linear expansion of the mortar 1, where the continuous layer was the bonding aggregate and the non-continuous layer was the fine aggregate, was calculated in first instance. Then, the coefficient of linear expansion of the mortal 2, where the continuous layer was the mortal 1 and the noncontinuous layer was a middle aggregate, was calculated. Lastly, the coefficient of linear expansion of the concrete when the continuous layer was the mortal 2 and the noncontinuous layer was a coarse aggregate was calculated. Here, in the case of the porous material or the sintered compact $(W \mathrm{e}=0)$ values of $V \mathrm{e}=W \mathrm{e}=10^{-6}$ were used. 


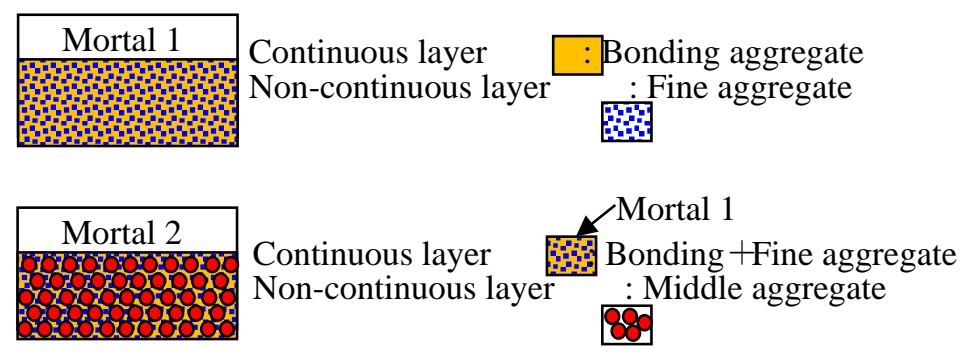

Figure 1: Models for calculation of thermal conductivity.

Young's modulus was calculated by eqn (5).

$$
E_{\mathrm{c}}=E_{\mathrm{t}}\left\{1+\frac{V_{\mathrm{d}}}{E_{\mathrm{d}} /\left(E_{\mathrm{d}}-E_{\mathrm{t}}\right)-V_{\mathrm{d}}^{1 / 3}}\right\},
$$

where $E$ was the Young's modulus [GPa]. In the case of concrete, the Young's modulus of the mortal 1, where the continuous layer was the bonding aggregate and the non-continuous layer was the fine aggregate, was calculated in first instance. Then, the Young's modulus of the mortal 2, where the continuous layer was the mortal 1 and the non-continuous layer was a middle aggregate, was calculated. Finally, the Young's modulus of the concrete when the continuous layer was the mortal 2 and the non-continuous layer was a coarse aggregate was calculated. Here, in the case of the porous material or the sintered compact $(W \mathrm{e}=0)$ values of $V \mathrm{e}=W \mathrm{e}=10^{-6}$ were employed.

\section{DEVELOPMENT OF A PHYSICAL PROPERTIES CALCULATION SOFTWARE}

A software for the calculation of the physical properties shown by new composite materials was developed. The flow chart for this software is shown in Fig. 2. The calculated properties were the Young's modulus, density, coefficient of linear expansion, specific heat and thermal conductivity. This software consisted of (1) the selection of several materials and the calculation of the constituent materials ratios to achieve certain desired properties in a new composite material (2) the calculation of the properties shown by the generated composite material based on the combination and ratio of its constituent materials, and (3) a data input based on a flexible constituent materials data base. Here, there were 60 kinds of aggregates and 5 kinds of bonding aggregates that could be changed or improved by the user at any time. Thus, when the user searches for a new composite material with certain hybrid propeties it is possible to achieve this through several materials and consituent material ratios.

From the software shown below, it was possible to simulate the creation of new composite materials based on the calculation of the constituent materials, their ratios and combination, along with the calculation of the Young's modulus, density, coefficient of linear

expansion, specific heat and thermal conductivity characteristics to verify that it complied with the physical properties desired by the user. Thus, given that this software provides the user with new composite material without even producing it, this can be particularly useful when performing CAE simulations. Here, designers can create new composite materials with certain desired properties and generate products with an increased quality, multifunctionality and high reliability based on the proposed method. 


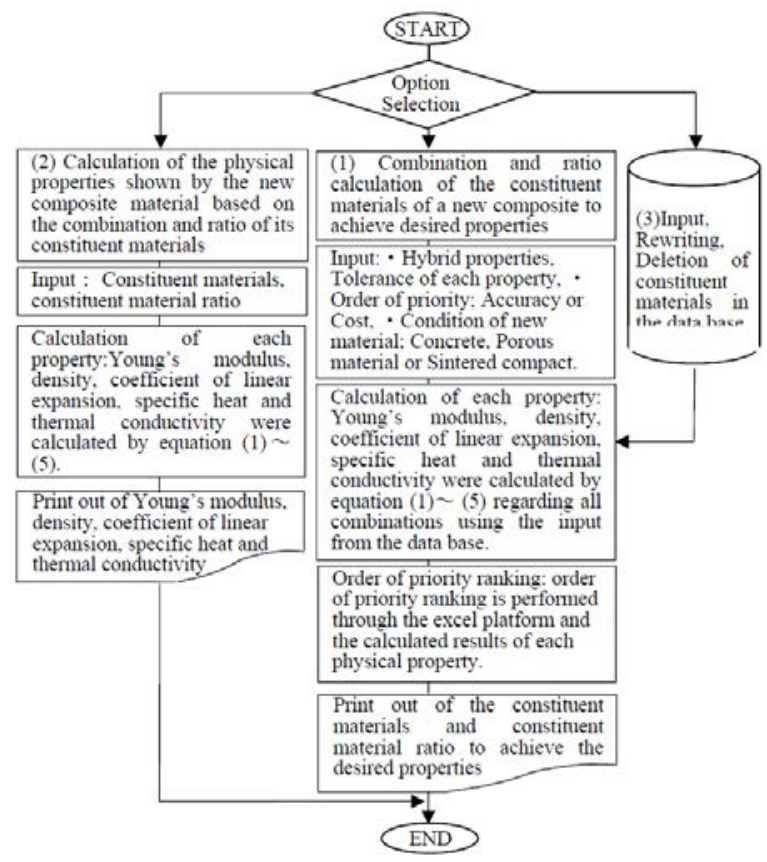

Figure 2: Flow chart of the developed software.

\section{THE COMPOSITE MATERIAL MANUFACTURING PROCEDURE}

The calculation models mentioned in Section 2 assume an homogeneous solid body. However, composites made through conventional manufacturing (mixing) generate an heterogeneous combination, which then becomes a defect. Therefore, as shown in Fig. 3, a new manufacturing method was developed to attend this issue [8], [9]. Specifically, coarse aggregate is firstly put into a mold. The mold is filled up with coarse aggregate up to about $60 \mathrm{vl} . \%$ of the mold. Then middle aggregate is added to the coarse aggregate and pressure and vibration are simultaneously applied to the mixture which generate a fixed body. Particularly, if the size of the middle aggregate is limited to less than one seventh of the coarse aggregate, the middle aggregate can fill up the space between the coarse aggregates. The middle aggregate is filled up $40 \mathrm{vl} . \%$ in the $60 \mathrm{vl} . \%$ space taken by the coase aggregate. Thus, the added middle aggregate represents a 24 vl.\% $(=0.4 \times 0.6)$. Consequently, the coarse and middle aggregates comprise a 84 vl.\% (=60 vl.\%+24 vl.\%) of the mold and the generated mixture is uniform. Subsequently, fine aggregate is added to fill the spaces between the middle aggregates.

Here, the fine aggregate represents about $10 \mathrm{vl} \%(=(100-60-24) \times 0.6)$. Thus, all aggregates comprise about $94 \mathrm{vl} \%$ (=60 vl.\%+24 vl.\%+10 vl.\%) of the mold, and each aggregate generate a perfectly uniform mixture. This, given that each space was filled by the aggregates in a rhombic display and the structure becomes a combination of mortar structure. In the end, a bonding aggregate such as epoxy resin is poured over the mixture of aggregates, and the air between the aggregates is pulled down from the bottom of the mold with a vacuum pump. This, makes the bonding aggregate to full the remaining space between the aggregates. After the bond become solid, the generated composite is removed. Thus, the distribution of each aggregate are similar to each of the proposed calculation model. 


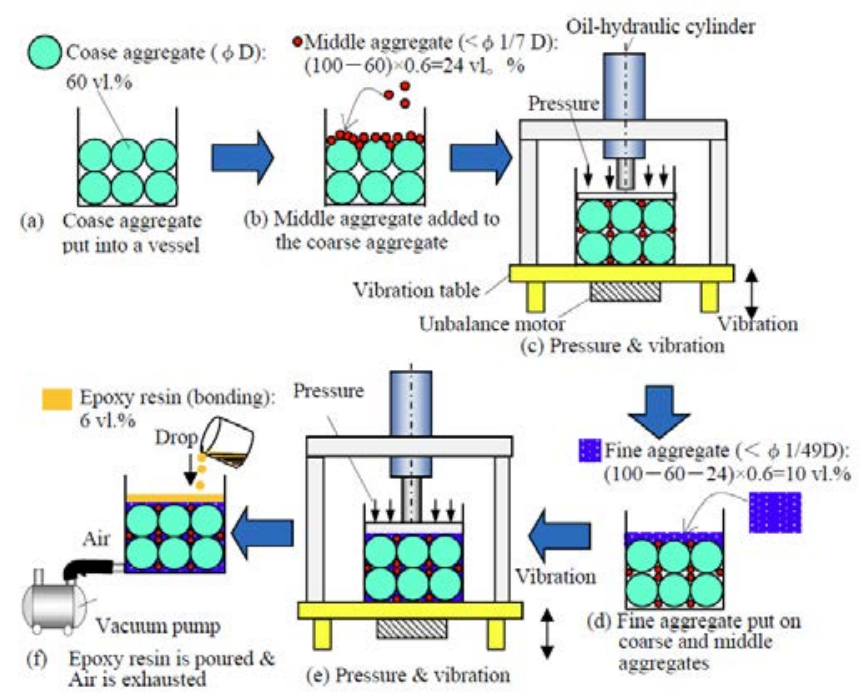

Figure 3: Manufacturing procedure for the generated composite material.

\section{EVALUATION OF THE DEVELOPED SOFTWARE}

The experimentation was based on the aforementioned procedure and gave ground to evaluate the software calculation accuracy. The results of density, coefficient of linear expansion and specific heat were accurate up to $\pm 5 \%$. However, the results of the Young's modulus and thermal conductivity were accurate up to $\pm 20 \%$. This was thought to be because of the formation of air in the composite material influences the accuracy of Young's modulus and thermal conductivity. Here, as the influence of the formation of air in the composite is considered and added using FEM simulation, calculation accuracy regarding the Young's modulus and thermal conductivity rose up to $\pm 5 \%$. Consequently, evaluation of the software was constrainted to the hybrid properties shown by generated composites during experimentation. Finally, the measurements of the physical properties were done using standard methods for this phenomena [9]-[12].

\section{MANUFACTURE OF A THREE-DIMENSIONAL FUNCTIONAL GRADIENT MATERIAL}

Given the aforementioned procedure and software, the ability to manufacture advanced materials was deemed as possible. In this regard, a three-dimensional functional gradient material (FGM) using the developed software was manufactured and evaluated for innovative materials development. These materials are known for having a quantitatively controlled gradation that is distance dependent to exhibit certain characteristics. Here, the FGM gradations can be tailored for several requirements which are mostly regarding physical properties and similar to the contents previously discussed in this research. However, there is little precedent regarding three-dimensional FGMs with multiple blocks. Particularly, the manufacturing procedure used for the generated FGM is shown in Fig. 4. The generated three-dimensional functional gradient material was a complex structure, the overall structure had several independent blocks with different constituent material arrangements. Here, each block with specific hybrid properties was arranged in the $\mathrm{X}, \mathrm{Y}$ 
and $\mathrm{Z}$ directions. The several hybrid properties of each block were calculated using the developed software and each block was manufactured using the procedure shown in Fig. 3. However, tap water was used instead of the epoxy resin used in Fig. 3, then the blocks were put into a freezer until the tap water froze. Subsequently, all blocks meant to form the FGM structure were taken out of the freezer and put into the mold shown in Fig. 4. This would assure that the individual blocks would in their place. Then the frozen tap water inside all the blocks was evaporated using a furnace. After this, the epoxy resin bonding aggregate was poured over all the blocks using Fig. 3(f). The final appearance of the manufactured three-dimensional functional gradient material (FGM) is shown in Fig. 5.

\section{FUTURE POSSIBILITIES AND CONSIDERATIONS REGARDING THE APPLICATION OF THE PROPOSED SOFTWARE AND METHODOLOGY}

This research consisted in the development of a software for the creation of new materials with hybrid properties. However, the boundaries of the proposed method were stretched

Table 1: Comparison of results for each calculation model.

\begin{tabular}{|c|c|c|c|c|c|c|c|c|}
\hline \multirow{2}{*}{\multicolumn{2}{|c|}{ Property }} & \multicolumn{3}{|c|}{ Aggregate } & \multirow{2}{*}{ Bond } & \multirow{2}{*}{$\begin{array}{l}\text { Calculated } \\
\text { value }\end{array}$} & \multirow{2}{*}{$\begin{array}{l}\text { Exp. } \\
\text { value }\end{array}$} & \multirow{2}{*}{ Error } \\
\hline & & Coarse & Middle & Fine & & & & \\
\hline \multirow{3}{*}{$\begin{array}{l}\text { Density } \\
\mathrm{kg} / \mathrm{m}^{3}\end{array}$} & 3150 & Alumina & Alumina & Alumina & \multirow{15}{*}{$\begin{array}{l}\text { Epoxy } \\
\text { resin }\end{array}$} & 3154 & 3100 & $-2 \%$ \\
\hline & 6500 & Steel & - & Steel & & 6552 & 6530 & $-3 \%$ \\
\hline & 2300 & - & - & $\begin{array}{l}\text { Silicon } \\
\text { carbide }\end{array}$ & & 2320 & 2310 & $-4 \%$ \\
\hline \multirow{3}{*}{$\begin{array}{l}\text { Thermal } \\
\text { conductivity } \\
\text { W/(mK) }\end{array}$} & 20 & Alumina & Alumina & Alumina & & 19.9 & 17.0 & $+7 \%$ \\
\hline & 9.3 & Steel & - & Steel & & 9.3 & 10.2 & $+9 \%$ \\
\hline & 1.5 & Glass & Glass & Glass & & 1.6 & 2.0 & $+20 \%$ \\
\hline \multirow{3}{*}{$\begin{array}{l}\text { Specific heat } \\
\mathrm{kJ} /(\mathrm{kgK})\end{array}$} & 0.9 & Alumina & Alumina & Alumina & & 0.92 & 0.90 & $-2 \%$ \\
\hline & 0.5 & Steel & - & Steel & & 0.53 & 0.49 & $-6 \%$ \\
\hline & 0.7 & $\begin{array}{l}\text { Silicon } \\
\text { carbide }\end{array}$ & $\begin{array}{l}\text { Silicon } \\
\text { carbide }\end{array}$ & $\begin{array}{l}\begin{array}{l}\text { Silicon } \\
\text { carbide }\end{array} \\
\end{array}$ & & 0.72 & 0.70 & $-2 \%$ \\
\hline \multirow{3}{*}{$\begin{array}{l}\text { Coefficient } \\
\text { linear } \\
\text { expansion } \\
\times 10^{-6} 1 / \mathrm{K}\end{array}$} & 11 & Alumina & Alumina & Alumina & & 11 & 11 & $0 \%$ \\
\hline & 17 & Steel & - & Steel & & 17 & 18 & $+6 \%$ \\
\hline & 30 & - & - & Alumina & & 29 & 28 & $+6 \%$ \\
\hline \multirow{3}{*}{$\begin{array}{l}\text { Young's } \\
\text { modulus } \\
\text { GPa }\end{array}$} & 160 & Alumina & Alumina & Alumina & & 160 & 152 & $-5 \%$ \\
\hline & 120 & Steel & - & Steel & & 126 & 109 & $-15 \%$ \\
\hline & 70 & Glass & Glass & Glass & & 66 & 60 & $-10 \%$ \\
\hline
\end{tabular}

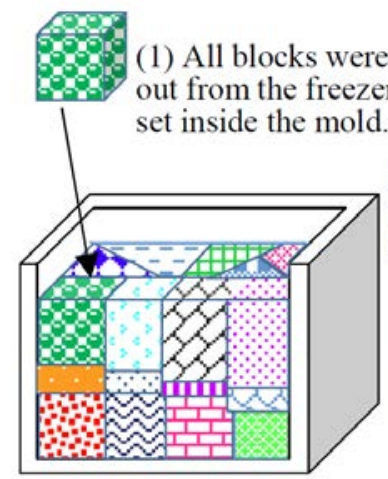

(1) All blocks were taken out from the freezer and set inside the mold.

(2) Water in the blocks was evaporated in a furnace

(3) Epoxy resin was poured over all blocks using Fig. 3(f) procedure

Figure 4: Manufacturing procedure for the three-dimensional functional gradient material. 


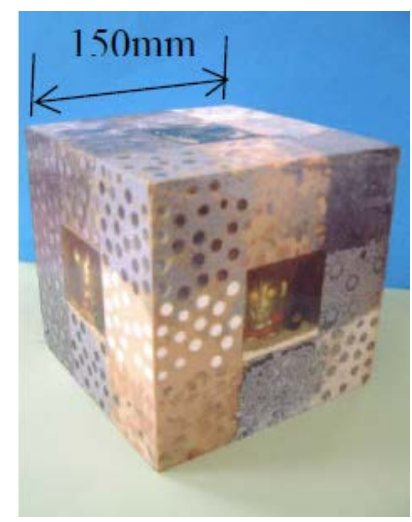

Figure 5: Generated three-dimensional functional gradient material.

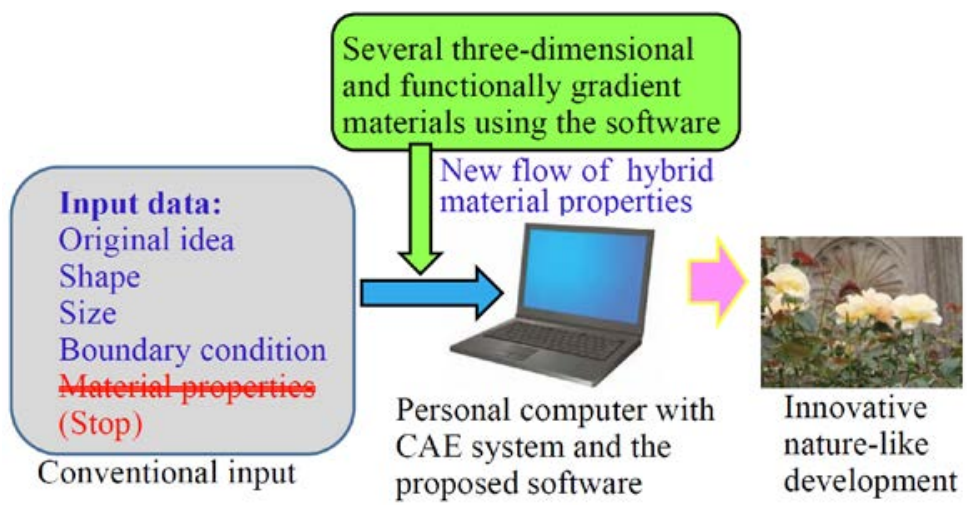

Figure 6: Innovative development using the proposed software

and an ongoing topic regarding advanced materials such as the functional gradient materials (FGM) was explored using the generated tools and manufacturing procedures in this research. Moreover, given that FGM originated from the mimicking of nature structures (e.g. leaves and insect exoskeletons), it is possible to say that innovation trends in the development of materials will follow a similar path. On the other hand, given that many many industrial products often require high quality, excellent physical properties and unique characteristics, innovative technology trends would need to comply with these demands. The proposed software is proposed to integrate both trends for a more nature-like technology development. For example, the proposed software could be integrated as shown in Fig. 6, most designers would be able to use the software in the early stages of CAE design development. Specifically, the standard input data during the design stages is the product concept, the shape, the size, the boundary conditions and the material properties. However, this stage is constrained to use the currently existing or available materials. As a consequence, the design stage is constrained to a defined amount of materials that exhibit certain physical properties. However, if a designer could have the possibility to generate their very own materials the design stage would be greatly improved. Therefore, the user 
would adapt the product to the user requirements instead of adapting the product to the available material constraint. As a result, new products using methodologies such as the proposed software, would exhibit a higher quality, originality and unique physical properties given that technology development would evolve in a more nature-like way.

\section{CONCLUSIONS}

It was concluded from the results that:

1. The proposed software could calculate several properties such as the Young's modulus, density, coefficient of linear expansion, specific heat and thermal conductivity.

2. Initial estimated values of density, coefficient of linear expansion and specific heat were each $\pm 5 \%$, however those of the Young's modulus and thermal conductivity were each $\pm 20 \%$. Additional FEM simulations were required to adjust the proposed software.

3. The software was deemed as effective and useful for development of new composite materials with hybrid properties given the final accuracy range of $\pm 5 \%$ that was obtained.

\section{REFERENCES}

[1] Moriwaki, T., Shamoto, E. \& Tokunaga, T., Thermal deformation of an ultraprecision machine tool due to environmental temperature change, Transactions of the Japan Society of Mechanical Engineers. Transaction of JSME, Series C, 63(615), pp. 4025-4030, 1997.

[2] Nakajima, H., Lotus-type porous metals. Bulletin of The Iron and Steel Institute of Japan, 6(9), pp. 701-707, 2001.

[3] Kobayashi, T., Matsubayashi, T. \& Shibata, K., On the improvement of the damping capacity of a steel structure by overlaying with fiber-reinforced plastics. Transaction of JSME, Series C, 58(554), pp. 3096-3101, 1992.

[4] Okada, M., Hosokawa, A., Asakawa, N., Fujita, Y. \& Ueda, T., Influence of Minimum Quantity Lubrication on Tool Temperature in End Milling of Difficult-toCut Materials Having Low Thermal Conductivity. Transaction of JSME, Series C, 78(792), pp. 3093-3103, 2012.

[5] Tanabe, I., Development of Technology for Creating Composite Materials of Machine Tool. Int. J. of Automation Technology, 9(6), pp. 714-719, 2015.

[6] Russell H.W., Principles of Heat Flow in Porous Insulators. J. Am. Ceram. Society, 18, pp. 1-5, 1956.

[7] Tanabe, I., Takada, K. \& Nakamura, A., Thermal and Mechanical Characteristics of Epoxy Resin Concrete Used in Machine Tool Structures. Transaction of JSME, Series C, 56(525), pp. 1314-1321, 1990.

[8] Tanabe, I., Mizutani, J. \& Yamada, Y., Development of Ceramic Resin Concrete for Precision Machine Tool Structures (Development of Three-Dimensional and Functionally Gradient Material). Transaction of JSME, Series C, 62(596), pp.16191625, 1996.

[9] Tanabe, I., Takiguchi, S. \& Iyama, T., Development of Software for Creating New Materials with Hybrid Properties. Transaction of JSME, Series C, 78(786), pp. 595604, 2012. 
[10] Tanabe, I., Takada, K. \& Nakamura, A., Thermal and Mechanical Characteristics of Epoxy Resin Concrete Used in Machine Tool Structures. Transaction of JSME, 56(525), pp. 1314-1321, 1990.

[11] Tanabe I., Mizutani J. \& Yamada, Y., Development of Ceramic Resin Concrete for Precision Machine Tool Structures (Development of Three-Dimensional and Functionally Gradient Material).Transaction of JSME, 62(596), pp. 1619-1625, 1996.

[12] Tanabe, I., Konndo, T., Yamada, Y. \& Mizutani, J., Development of ThreeDimensional and Functionally Gradient Material and Evaluation of the Composite Structure Lathe Using the Material. Transaction of JSME, 64(627), p. 4472, 1998. 